\title{
Aqueous phase/nanoparticles interface: hydroxypropyl cellulose adsorption and desorption triggered by temperature and inorganic salts $\dagger$
}

\author{
G. Cavallaro, G. Lazzara* and S. Milioto \\ Received 21st October 2011, Accepted 17th January 2012 \\ DOI: $10.1039 / \mathrm{c} 2 \mathrm{sm} 07021 \mathrm{a}$
}

The study highlighted the main forces driving the adsorption of hydroxypropyl cellulose (HPC) onto clay nanoparticles with a disk-like shape (Laponite RD). Modeling the isothermal titration calorimetry data provided the key thermodynamic properties, which enabled us to discuss the microscopic aspects contributing to the energetic and the entropic changes of the polymer adsorption at the nanoparticle/ liquid interface. We evidenced that the process is strongly enthalpy-driven and that the interactions lead to constraints of the HPC configuration at interface. The functionalized nanoparticles enhanced the polymer solubility in water expanding the one-phase area of the binodal curve. Temperature and salts change the forces of adsorption and, furthermore, salts generate a dramatic reduction of the HPC solubility in water in the presence of Laponite RD.

\section{Introduction}

Over the last few years several polymers from natural resources or biocompatible have been investigated because their use in combination with other additives may form new structures with potential technological applications. ${ }^{1-6}$ Designing new nanomaterials composed of biopolymer and nanoparticles environmental friendly is a challenging task. Within this issue, hydroxypropyl cellulose (HPC) assumes a particular interest. It is a biopolymer obtained from the chemical modification of the cellulose and, in particular, the propylene oxide is linked to the anhydroglucose hydroxyl groups. The physico-chemical behavior of HPC is well known based also on its rather high solubility in water although it is hydrophobically modified. HPC undergoes phase separation upon heating, ${ }^{7}$ and it is able to form liquid crystals. ${ }^{8}$ Interactions between HPC molecules at close separation were evidenced by means of the osmotic stress method coupled with X-ray scattering. ${ }^{9}$ This polymer has been used in the consolidation of waterlogged woods and it was revealed very efficient even if optimization of the impregnation process was necessary. ${ }^{10} \mathrm{HPC}$ is used in preparing organic-inorganic nanocomposites because it ensures the stabilization and the homogeneous dispersions of inorganic salts. ${ }^{11}$ The role of the solvent nature (water and ethanol) in the performance of the obtained films was investigated. ${ }^{12}$ Finally, HPC assembled with poly(acrylic acid) onto nanoparticles provided long term stability microcapsules for controlled drug delivery applications. ${ }^{5}$

Dipartimento di Chimica "S. Cannizzaro", Università degli Studi di Palermo, Viale delle Scienze, Parco D'Orleans II, Pad. 17, 90128 Palermo, Italy.E-mail: giuseppe.lazzara@unipa.it

$\dagger$ Electronic supplementary information (ESI) available. See DOI: $10.1039 / \mathrm{c} 2 \mathrm{sm} 07021 \mathrm{a}$
As concerns the nanoparticles, nanoclays are of some interest because they are environmentally friendly and available at low cost. Several studies have been devoted to the physico-chemical characterization of aqueous nanoclay dispersions in the presence of adsorbing species. ${ }^{13-16}$ Laponite RD is a synthetic clay that forms charge-stabilized colloidal dispersion in water. ${ }^{17}$ The net charge of a single particle is negative and it is due to the negatively charged faces and slightly positive edge. ${ }^{17}$

We thought that HPC may be adopted to functionalize surfaces of solid substrates through non-covalent forces and its interactions with Laponite RD may generate new materials. Being that HPC was approved by the United States Food and Drug Administration, ${ }^{18}$ it is recurrent within the pharmaceutical technology and films of HPC have been designed accordingly. ${ }^{19}$ Within this issue, we thought it would be interesting to perform a thermodynamic, structural and surface tension study on the aqueous mixtures of HPC and Laponite RD in dependence of the concentration of both the polymer and the nanofiller. Temperature and inorganic salts were selected as parameters to trigger the adsorption process. The thermodynamic properties were obtained from isothermal titration calorimetry and differential scanning calorimetry studies while the diffusion behaviour of the nanoparticles was described by the dynamic light scattering technique. Surface tension experiments evidenced the adsorption phenomenon occurring in the bulk phase.

\section{Materials and methods}

\section{Chemicals}

Hydroxypropyl cellulose (weight average molecular mass = $80 \mathrm{~kg} \mathrm{~mol}^{-1}$ and number average molecular mass $=10 \mathrm{~kg} \mathrm{~mol}^{-1}$ ) and $\mathrm{NaCl}(99.999 \%)$ are Sigma products. $\mathrm{KCl}(99.99 \%)$ is from 
Merck and $\mathrm{LiCl}(99.99 \%)$ is from Riedel-de-Hoën, AG. Laponite RD grade was a gift from Azelis Italia S.r.l. and it was used as received. It has the molecular formula ${ }^{17} \mathrm{Si}_{8}\left(\mathrm{Mg}_{5.45} \mathrm{Li}_{0.4}\right)$ $\mathrm{O}_{20}(\mathrm{OH})_{4} \mathrm{Na}_{0.7}$ constituting the unitary cell of the disk-like clay platelet with a diameter of about $25 \mathrm{~nm}$ and a thickness of $1 \mathrm{~nm}$. The molar mass of the Laponite RD unit cell is $764.55 \mathrm{~g} \mathrm{~mol}^{-1}$. Water from reverse osmosis (Elga model Option 3) with a specific resistivity greater than $1 \mathrm{M} \Omega \mathrm{cm}$ was used. The water content of $2.9 \mathrm{wt} \%$ for the polymer was determined by thermo-gravimetry.

\section{Samples preparation}

Laponite $\mathrm{RD}$ dispersion was prepared according to the literature procedure. ${ }^{17}$ Briefly, nanoclay powder was added to water and the mixture was kept under stirring for at least 3 hours before the measurements. Aqueous hydroxypropyl cellulose (HPC) solution was prepared by mixing under vigorous stirring for $c a$. 2 hours a certain amount of polymer with water at $60{ }^{\circ} \mathrm{C}$. The solution was left to equilibrate at room temperature under stirring overnight. The final polymer concentration was evaluated by weight.

\section{Differential scanning calorimetry (DSC)}

The micro-DSC III 106 (Setaram) under nitrogen flow in the range from 5 to $80^{\circ} \mathrm{C}$ with a scan rate of $0.6{ }^{\circ} \mathrm{C} \mathrm{min}^{-1}$ was used. The stainless steel $\left(1 \mathrm{~cm}^{3}\right)$ sample cell contained ca. $500 \mathrm{mg}$ of solution while the reference cell was filled with a comparable amount of water. The calibration was performed by using naphthalene.

For all the aqueous HPC solution in the absence and the presence of Laponite $\mathrm{RD}$, a single endothermic phenomenon was observed and ascribed to the cloud point of HPC in agreement with the literature. ${ }^{7,20}$ Examples of thermograms are collected in the ESI $\dagger$. The cloud temperature $\left(t_{\mathrm{C}}\right)$ at the maximum of the peak as well as the corresponding enthalpy $\left(\Delta H_{\mathrm{C}}\right)$ from the integration of the thermogram were determined. The baseline was subtracted according to the literature. ${ }^{21}$ The measurements were carried out at a fixed HPC concentration by systematically changing the Laponite RD amount. The investigated solvent media are water

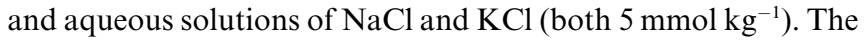
uncertainty in $t_{\mathrm{C}}$ is $\pm 0.1{ }^{\circ} \mathrm{C}$ and in $\Delta H_{\mathrm{C}}$ is $3 \%$.

Experiments performed on some dispersions in a week-range did not evidence time effects (data are in the ESI $\dagger$ ).

\section{Isothermal titration calorimetry (ITC)}

The ITC experiments were performed by using the ultrasensitive nano-ITC200 calorimeter (MicroCal). The amount of approximately $40 \mu \mathrm{L}$ of the water + HPC mixture was injected into the thermally equilibrated ITC cell $(200 \mu \mathrm{L})$ containing the water + Laponite RD dispersion. Under the same experimental conditions, the dilution of the aqueous HPC solution and the Laponite $\mathrm{RD}$ dispersion with water were carried out. The temperature was changed from 5 to $45^{\circ} \mathrm{C}$. The effect of salt addition was investigated at $15^{\circ} \mathrm{C}$; namely, aqueous solutions of $\mathrm{NaCl}, \mathrm{KCl}$ and

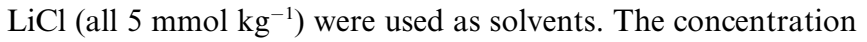

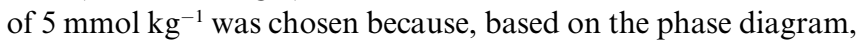
larger salt amounts generate the nanoclay precipitation. ${ }^{22}$

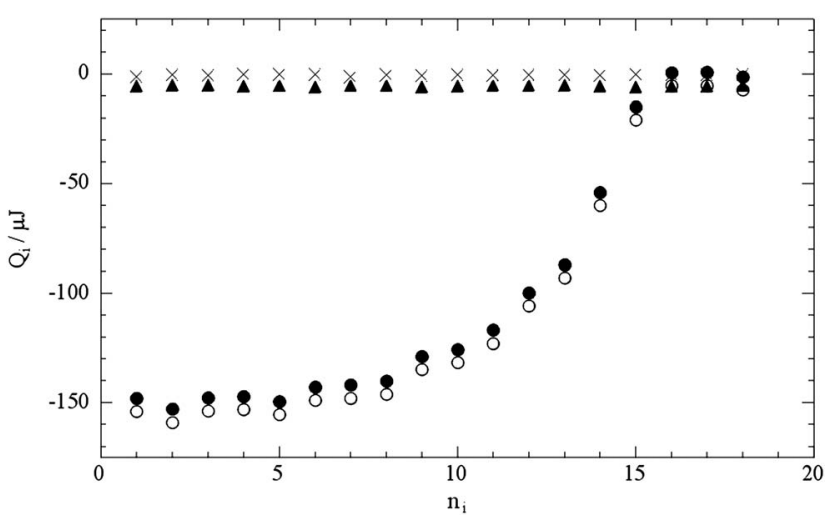

Fig. 1 Dependence on the number of injections of the heats of injection of the HPC solution into water $(\boldsymbol{\Delta})$, of water into the Laponite RD dispersion $(\times)$, of the HPC solution into the Laponite RD dispersion $(O)$ and heat of interaction $(\bullet)$ at $25^{\circ} \mathrm{C}$.

Fig. 1 illustrates an example of the enthalpic effects for a complete titration experimental set; namely, the dependence on the number of injections $\left(n_{\mathrm{i}}\right)$ of the heats of injection of the aqueous HPC solution into water $\left(Q_{\mathrm{HPC}}\right)$, of water into the aqueous Laponite RD dispersion $\left(Q_{\mathrm{L}}\right)$ and of the aqueous HPC solution into the aqueous Laponite $\mathrm{RD}$ dispersion $\left(Q_{\mathrm{HPC} / \mathrm{L}}\right)$ is reported. Moreover, $Q_{\mathrm{HPC} / \mathrm{L}}$ corrected for the dilution effects $\left(Q_{\mathrm{HPC}}\right.$ and $\left.Q_{\mathrm{L}}\right)$ is also shown $\left(Q_{\mathrm{i}}\right)$. The heat of interaction per mole of HPC $\left(\Delta H_{\mathrm{i}}\right)$ was calculated as $Q_{\mathrm{i}} /\left(V_{\mathrm{a}} M_{\mathrm{P}}\right)$ being $V_{\mathrm{a}}$ the volume of each addition and $M_{\mathrm{P}}$ the polymer molarity. Both the dilution heats are slightly negative and almost negligible. $Q_{\mathrm{L}}$ is consistent with the negative dilution enthalpies of aqueous Laponite RD dispersion with water. ${ }^{23}$

\section{Surface tension}

A programmable tensiometer (KSV Sigma 70) equipped with a Wilhelmy plate was employed at $25.0 \pm 0.1{ }^{\circ} \mathrm{C}$. A concentrated polymer solution (being the solvent water or water $+\mathrm{NaCl}$ ) was added to the corresponding solvent to obtain various polymer concentrations. Moreover, the presence of Laponite RD was investigated as detailed in the following. A concentrated polymer in the solvent (water or water $+\mathrm{NaCl}$ ) was added to the Laponite $\mathrm{RD}$ dispersion in the corresponding solvent to obtain several polymer concentrations. The $\mathrm{NaCl}$ and Laponite RD concentrations are 5 and $0.4 \mathrm{mmol} \mathrm{kg}^{-1}$, respectively. The additions of the polymer solution were done to cover a proper range of polymer/Laponite RD ratio based on the ITC experiments. The surface tension of each mixture was determined at the equilibrium. Each surface tension value is the average of three determinations and its precision is 0.1 dyne $\mathrm{cm}^{-1}$.

\section{Dynamic light scattering}

The measurements were performed at $18.0 \pm 0.1{ }^{\circ} \mathrm{C}$ in a sealed cylindrical scattering cell at a scattering angle of $90^{\circ}$ by means of a Brookhaven Instrument apparatus composed of an BI-9000AT correlator and a $\mathrm{He}-\mathrm{Ne}$ laser $(75 \mathrm{~mW})$ with a wavelength $(\lambda)$ of $632.8 \mathrm{~nm}$. The solvent was filtered by means of a Millipore filter with $0.45 \mu \mathrm{m}$ pore size. 
The field-time autocorrelation functions were well described by a mono-exponential decay function, which provides the decay rate $(T)$ correlated to the apparent diffusion coefficient $(D)$

$$
D=\Gamma / q^{2}
$$

where $q$ is the scattering vector given by $4 \pi n \lambda^{-1} \sin (\theta / 2)$ being $n$ the water refractive index and $\theta$ the scattering angle. The apparent hydrodynamic radius $\left(R_{\mathrm{h}}\right)$ was calculated by using the Stokes-Einstein equation and the water viscosity value. Examples of mono-exponential fitting are collected in the ESI $\dagger$. The hydrodynamic radius of the Laponite RD in water agrees with the literature. ${ }^{24,25}$

\section{Results}

\section{Isothermal titration calorimetry studies}

Fig. 2a shows the effect of the polymer/Laponite RD mole ratio $\left(R_{\mathrm{HPC}: \mathrm{L}}\right)$ on the heat of interaction per mole of $\mathrm{HPC}\left(\Delta H_{\mathrm{i}}\right)$ from 5 to $45{ }^{\circ} \mathrm{C}$. At a given temperature, the $\Delta H_{\mathrm{i}} v s$. $R_{\mathrm{HPC}: \mathrm{L}}$ profile describes a sigmoidal curve that reaches null values at the highest $R_{\mathrm{HPC}: \mathrm{L}}$ values. Upon increasing the temperature $\Delta H_{\mathrm{i}}$ assumes more and more negative values generating sharper $\Delta H_{\mathrm{i}} v s$. $R_{\mathrm{HPC}: \mathrm{L}} \mathrm{S}$-shaped curves; moreover, the inflection point of each trend is essentially independent of temperature.

The electrolyte generates relevant effects on the $\Delta H_{\mathrm{i}} v s$. $R_{\text {HPC:L }}$ curves (Fig. 2b). The addition of $\mathrm{NaCl}$ shifts the enthalpic curve towards negative values while it does not alter the $R_{\mathrm{HPC}: \mathrm{L}}$ at the inflection point. Differently, both $\mathrm{KCl}$ and

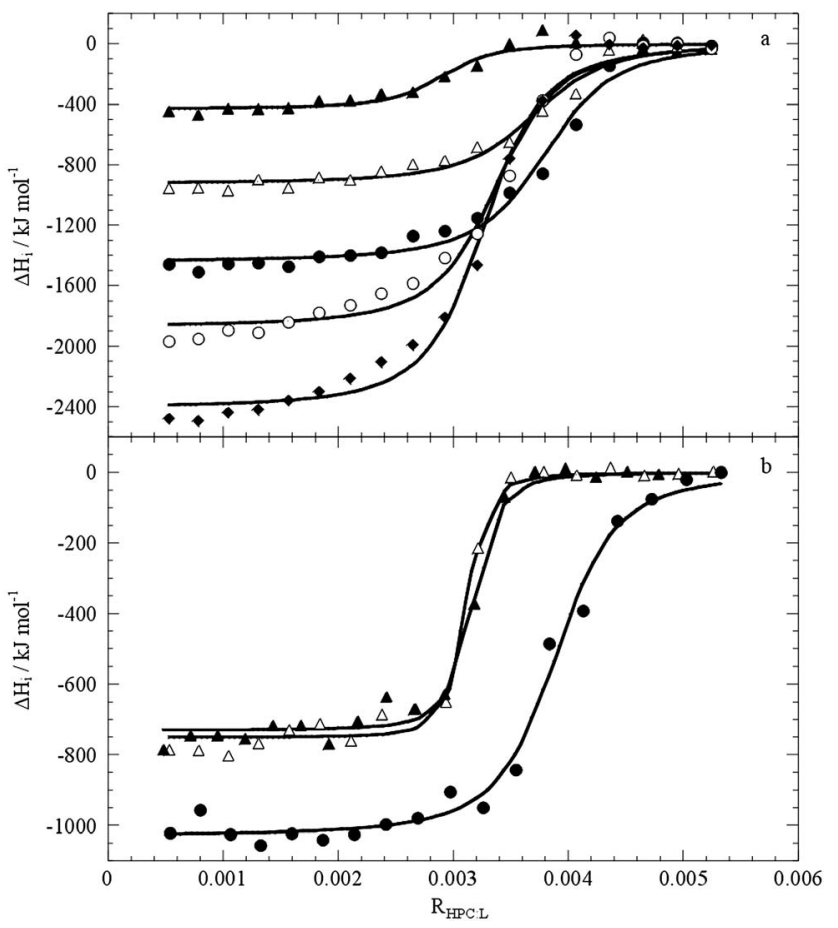

Fig. 2 Heat of interaction per mol of HPC as functions of the HPC/ Laponite RD unit cell mole ratio in the absence (a) and the presence (b) of salts. (a) $5{ }^{\circ} \mathrm{C}(\boldsymbol{\Delta}), 15^{\circ} \mathrm{C}(\triangle), 25^{\circ} \mathrm{C}(\bullet), 35^{\circ} \mathrm{C}(\bigcirc)$ and $45^{\circ} \mathrm{C}(\bullet)$. (b) $\mathrm{LiCl}(\boldsymbol{\Delta}), \mathrm{NaCl}(\bullet)$ and $\mathrm{KCl}(\triangle)$, all $5 \mathrm{mmol} \mathrm{kg}{ }^{-1}$ and $15^{\circ} \mathrm{C}$. Lines are best fits according to eqn (2)-(6).
$\mathrm{LiCl}$ shift the inflection point toward smaller $R_{\mathrm{HPC}: \mathrm{L}}$ values and the observed heat effects are smaller than the corresponding data in water. These results reveal specificity of the interactions between the HPC and the Laponite RD triggered by the presence of electrolytes, which can alter the energetics of the adsorption process as well as the HPC/Laponite RD stoichiometry of interaction.

The $\Delta H_{\mathrm{i}} v s . R_{\mathrm{HPC}: \mathrm{L}} \mathrm{S}$-shaped curve reflects a single adsorption process interpretable by means of simple models, which have been revealed successful for the adsorption of macromolecules onto nanoparticles in water..$^{23,26,27}$ We assume that Laponite RD exhibits a total moles of adsorption sites per litre of water $\left(S_{\mathrm{t}}\right)$ given $b^{23}$

$$
S_{\mathrm{t}}=Z\left[M_{\mathrm{L}}\right]
$$

where $\left[M_{\mathrm{L}}\right]$ is the Laponite RD concentration in formula unit molarity and $Z$ is the moles of sites contained in 1 mole of Laponite RD formula unit.

The equilibrium constant is

$$
K_{\mathrm{ads}}=\frac{S_{1}}{\left[M_{\mathrm{pw}}\right] S_{\mathrm{f}}}
$$

where $S_{1}$ represents the moles of sites per litre of mixture occupied by the polymer, whereas $S_{\mathrm{f}}$ is the moles of free sites per litre of mixture; $\left[M_{\mathrm{pw}}\right]$ stands for unbound polymer molarity.

The injection heat for the $i^{\text {th }}$ titration step is given by

$$
Q_{i}=Q_{j}-Q_{j-1}+\left(Q_{j}+Q_{j-1}\right) V_{\mathrm{a}} / 2 V_{\mathrm{c}}
$$

For the $j^{\text {th }}$ and $\left(j^{\text {th }}-1\right)$ states before and after the $i^{\text {th }}$ addition step the corresponding $Q_{j}$ and $Q_{j-1}$ are

$$
\begin{gathered}
Q_{j}=\left[M_{\mathrm{P}}\right]_{j} V_{\mathrm{c}} \Delta H^{\circ}{ }_{\text {ads }}\left[X_{\mathrm{ads}}\right]_{j} \\
Q_{j-1}=\left[M_{\mathrm{P}}\right]_{j-1} V_{\mathrm{c}} \Delta H^{\circ}{ }_{\mathrm{ads}}\left[X_{\mathrm{ads}}\right]_{j-1}
\end{gathered}
$$

where $\Delta H^{\circ}$ ads is the enthalpy of adsorption per mole of polymer, $V_{\mathrm{c}}$ is the cell volume and $X_{\text {ads }}$ is the fraction of adsorbed polymer controlled by the equilibrium constant.

Note that the third term at the right hand side of eqn (4) is the correction for the displaced volume. ${ }^{28}$

According to eqn (2)-(6) the experimental data (Fig. 2) were successfully fitted and provided $K_{\text {ads }}, Z$ and $\Delta H^{\circ}$ ads. The minimizing procedure was performed by means of the non-linear least-squares fitting based on the Levenberg-Marquardt algorithm.

The standard free energy and entropy for the adsorption process were calculated as:

$$
\Delta G_{\text {ads }}^{\circ}=-R T \ln K_{\mathrm{ads}}, T \Delta S_{\mathrm{ads}}^{\circ}=\Delta H_{\mathrm{ads}}^{\circ}-\Delta G^{\circ} \text { ads }
$$

From the $Z$ value, the adsorbed amount of HPC $\left(Z^{*}\right)$ per Laponite RD surface area was calculated by using the Laponite RD specific area of $200 \mathrm{~m}^{2} \mathrm{~g}^{-1} \cdot \cdot^{24,29}$

The adsorption of the polymer at the solid/liquid interface is entropy driven. As Fig. 3 shows, $\Delta S^{\circ}$ ads and $\Delta H^{\circ}$ ads compensate for each other, and their temperature slope is negative. Such a compensation is a real phenomenon related to the hydrophobic effect as proved by a statistical test ${ }^{30,31}$ applied to our data. As 


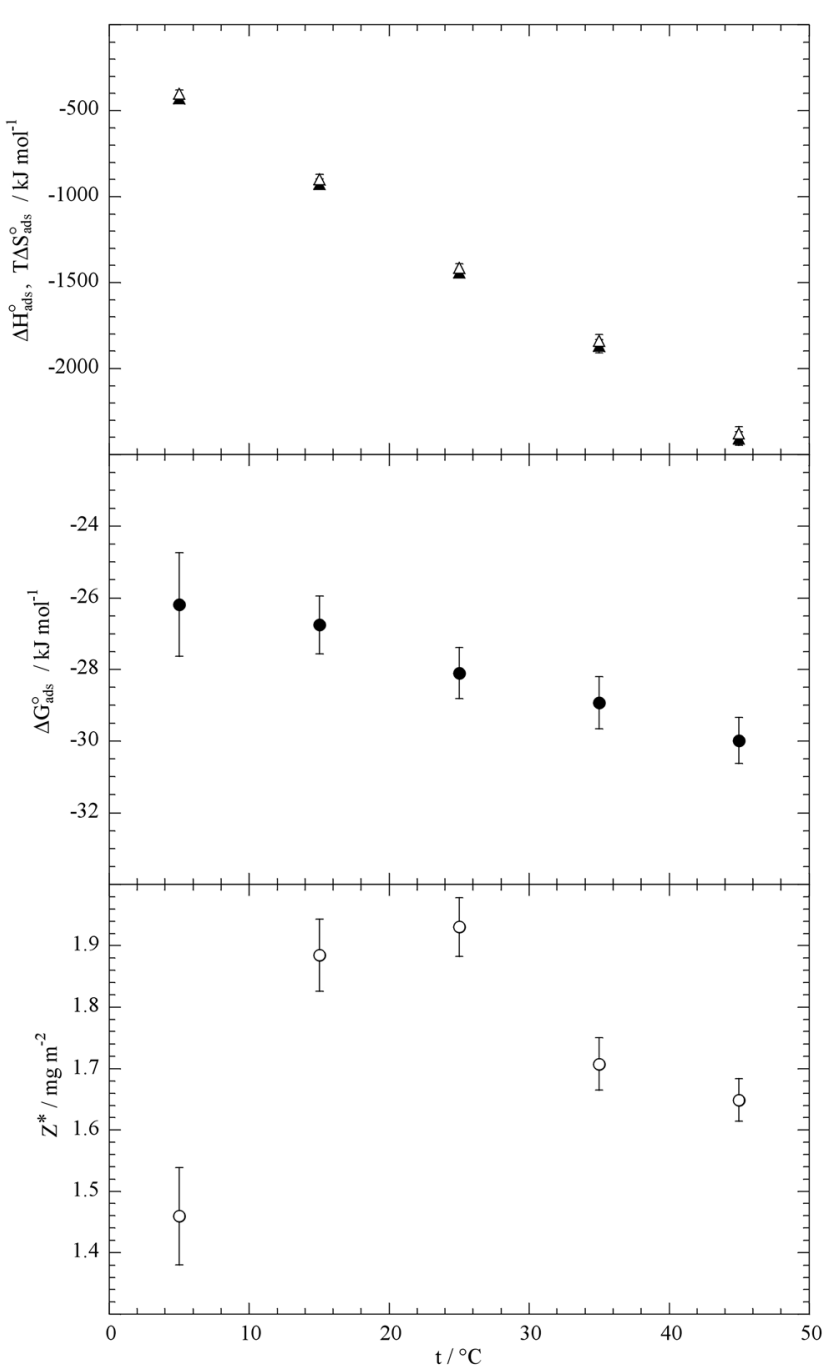

Fig. 3 Standard free energy ( $\bullet$ ), enthalpy $(\boldsymbol{\Delta})$, entropy $(\triangle)$ and stoichiometry $(\bigcirc)$ for the HPC adsorption onto aqueous Laponite RD at various temperatures.

concerns $Z^{*}$, it exhibits a slight change with temperature with a maximum at $25^{\circ} \mathrm{C}$ (Fig. 3).

The salts do not affect the mechanism of adsorption but they slightly enhance the adsorption process (see $\Delta G^{\circ}$ ads in Table 1) making the HPC less soluble in water. ${ }^{9}$ Compared to the values in water, $\Delta H^{\circ}$ ads increases in the presence of $\mathrm{LiCl}$ and $\mathrm{KCl}$, while it decreases in the presence of $\mathrm{NaCl}$ (Fig. 4). A similar trend was observed for the $Z^{*}$ values (Table 1 ).

Table 1 Standard free energy and stoichiometry for the HPC adsorption onto Laponite RD in water and in the presence of $\mathrm{LiCl}, \mathrm{NaCl}$ and $\mathrm{KCl}$, all $5 \mathrm{mmol} \mathrm{kg}^{-1}$ and $15^{\circ} \mathrm{C}^{a}$

\begin{tabular}{lll}
\hline & $\Delta G^{\circ}$ ads & $Z^{*}$ \\
\hline Water & $-26.7 \pm 0.8$ & $1.88 \pm 0.06$ \\
$\mathrm{LiCl}$ & $-31.1 \pm 0.9$ & $1.60 \pm 0.02$ \\
$\mathrm{NaCl}$ & $-31.3 \pm 0.6$ & $1.97 \pm 0.03$ \\
$\mathrm{KCl}$ & $-32.4 \pm 1.1$ & $1.56 \pm 0.02$
\end{tabular}

${ }^{a}$ Units are: $\Delta G^{\circ}$ ads, $\mathrm{kJ} \mathrm{mol}^{-1}$ and $Z^{*}, \mathrm{mg} \mathrm{m}^{-2}$.

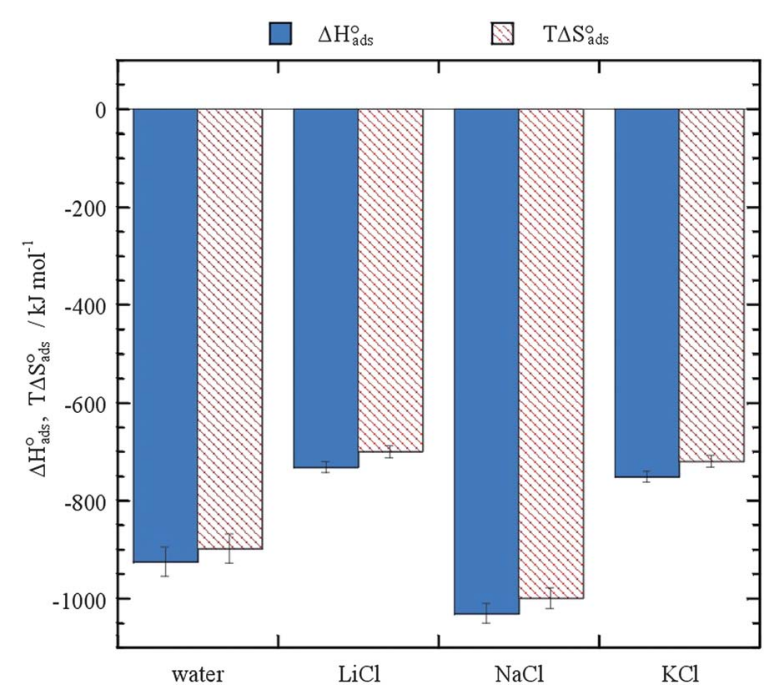

Fig. 4 Standard enthalpy and entropy for the HPC adsorption onto aqueous Laponite $\mathrm{RD}$ in the absence and the presence of $\mathrm{LiCl}, \mathrm{NaCl}$ and $\mathrm{KCl}$, all $5 \mathrm{mmol} \mathrm{kg}{ }^{-1}$ and $15^{\circ} \mathrm{C}$.

\section{Diffusion of aqueous Laponite RD in the presence of HPC}

In the investigated HPC concentration regime, the scattering intensity of the polymer solution, in the absence of nanoparticles, was very low and it did not allow us to obtain a reliable correlation function to determine the HPC diffusion coefficient. The fact that Laponite RD can be easily monitored while HPC appears invisible is ascribable to the dispersed material-water contrast differences, given by the refractive indexes. In particular, for Laponite $\mathrm{RD},{ }^{32} \mathrm{HPC}^{33}$ and water the refractive index values are 1.51, 1.34 and 1.33, respectively. Nevertheless, the results obtained for the aqueous Laponite RD/HPC mixtures are rather interesting. As Fig. 5 shows, the hydrodynamic radius $\left(R_{\mathrm{h}}\right)$ linearly increases with the $R_{\mathrm{HPC}: \mathrm{L}}$. Even if the polymer does not scatter much in water, one can ascribe such an increase to the polymer adsorption onto the solid surface. In fact, the Laponite RD particle covered by HPC has a slower dynamics than the bare Laponite RD and it maintains a sufficient scattering intensity. The maximum change in $R_{\mathrm{h}}$ is of $c a .20 \mathrm{~nm}$ and it is of the same order of magnitude of the variation observed ${ }^{25}$ for adsorbing

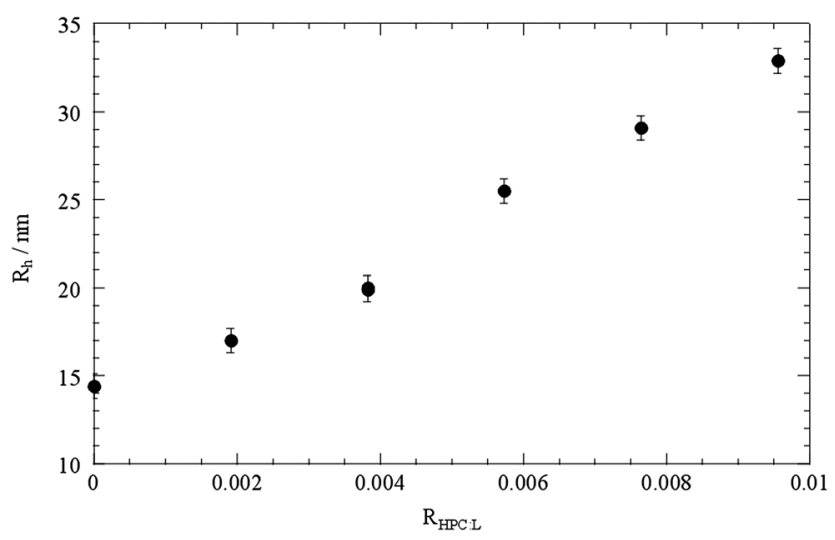

Fig. 5 Apparent hydrodynamic radius of HPC/Laponite RD mixtures in the aqueous phase as a function of their mole ratio. 
poly(ethyleneglycols) with a molecular mass similar to the present HPC.

\section{Differential scanning calorimetry studies}

It is well known that HPC undergoes phase separation upon heating because the water cages surrounding the hydrophobic moieties of the polymer molecule melt. ${ }^{6}$ The addition of Laponite $\mathrm{RD}$ generates a big effect on the cloud behavior of the polymer; namely, $t_{C}$ increases describing a sigmoidal profile (Fig. 6), which indicates that the role of the Laponite RD on the HPC solubility is rather complex. The enlargement of the one-phase region in the presence of Laponite RD may be a consequence of the HPC adsorption onto the solid surface; in other words, the amount of free HPC is decreased and the solubility is increased. We also monitored the effect of the electrolytes and, in particular, $\mathrm{NaCl}$ and $\mathrm{KCl}$ were selected because they exhibited different adsorption behavior onto the Laponite RD surface. It is rather

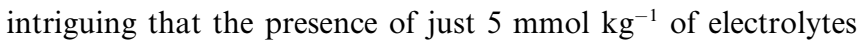
generates a $t_{\mathrm{C}}$ which diminishes upon Laponite RD addition (Fig. 6). It appears that the electrolytes play a relevant salting out effect in the presence of Laponite RD because not only they cancel the improvement of the HPC solubility created by the nanoparticles but also make $t_{\mathrm{C}}$ lower than the value in water (Fig. 6).

Salts lower the HPC cloud-point transition temperature in water but at a concentration much larger than those investigated here. ${ }^{9,20,34} \mathrm{Xia}$ et $a l^{.34}$ ascribed such an effect to the weakening of hydrogen bonding between HPC and water. The mechanism that salts act indirectly on HPC precipitation through its exclusion

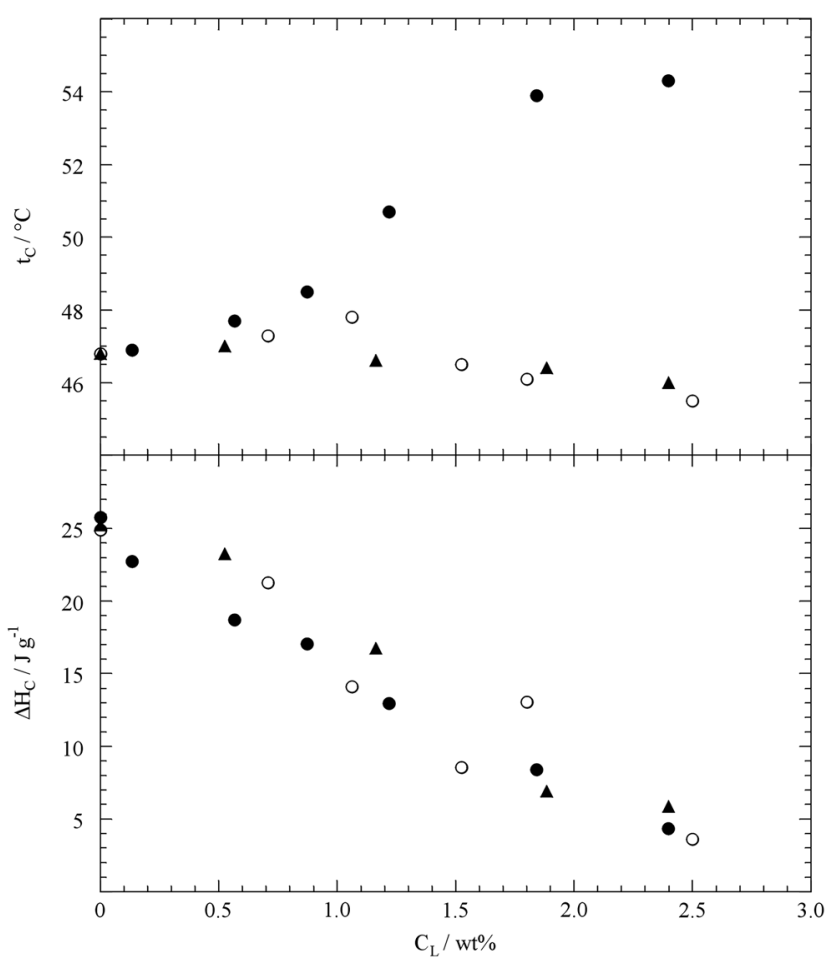

Fig. 6 Dependence on the Laponite RD concentration for temperature and enthalpy of the HPC phase separation in the absence (O) and the presence of $\mathrm{NaCl} 5 \mathrm{mmol} \mathrm{kg}{ }^{-1}(\mathrm{O})$ and $\mathrm{KCl} 5 \mathrm{mmol} \mathrm{\textrm {kg } ^ { - 1 }}(\boldsymbol{\Delta})$. from the condensed phase was also invoked..$^{9,20,34}$ Our systems are rather complex and the presence of the nanoclay generates a more relevant salt effect on the HPC cloud behavior.

As concerns $\Delta H_{\mathrm{C}}$, it diminishes upon the nanoclay addition and the presence of Laponite RD $2.5 \mathrm{wt} \%$ reduces the enthalpy by one order of magnitude (Fig. 6). The electrolytes do not much alter $\Delta H_{\mathrm{C}}$ whatever is their nature (Fig. 6). The $\Delta H_{\mathrm{C}}$ change in the presence of Laponite RD is consistent with the reduced number of macromolecules that undergo the phase separation as a consequence of their interactions with the nanoparticles.

\section{Surface tension of the aqueous HPC solutions in the presence of Laponite $\mathrm{RD}$ and $\mathrm{NaCl}$}

To understand in a comprehensive manner the role played by the electrolyte and the nanoparticles on the HPC behaviour at the interface, the surface tension $(\gamma)$ investigation was extended to the $\mathrm{HPC}+$ Laponite $\mathrm{RD}+\mathrm{NaCl}+$ water mixtures by changing the polymer concentration $\left(C_{\mathrm{P}}, \mathrm{wt} \%\right)$ and keeping constant the concentrations of $\mathrm{NaCl}\left(5 \mathrm{mmol} \mathrm{kg}^{-1}\right)$ and Laponite $\mathrm{RD}$ $\left(0.4 \mathrm{mmol} \mathrm{kg} \mathrm{kg}^{-1}\right)$. For a comparison purpose, the HPC + water and $\mathrm{HPC}+\mathrm{NaCl}+$ water mixtures as functions of $C_{\mathrm{P}}$ were also studied.

As Fig. 7a illustrates, HPC strongly lowers $\gamma$ of water even at very low concentration and the values agree with the literature reports. ${ }^{35}$ The presence of $\mathrm{NaCl}$ does not alter much $\gamma$ values. The Gibbs equation applied to $\gamma$ data of HPC in water and water $+\mathrm{NaCl}$ mixture allowed us to estimate the HPC surface

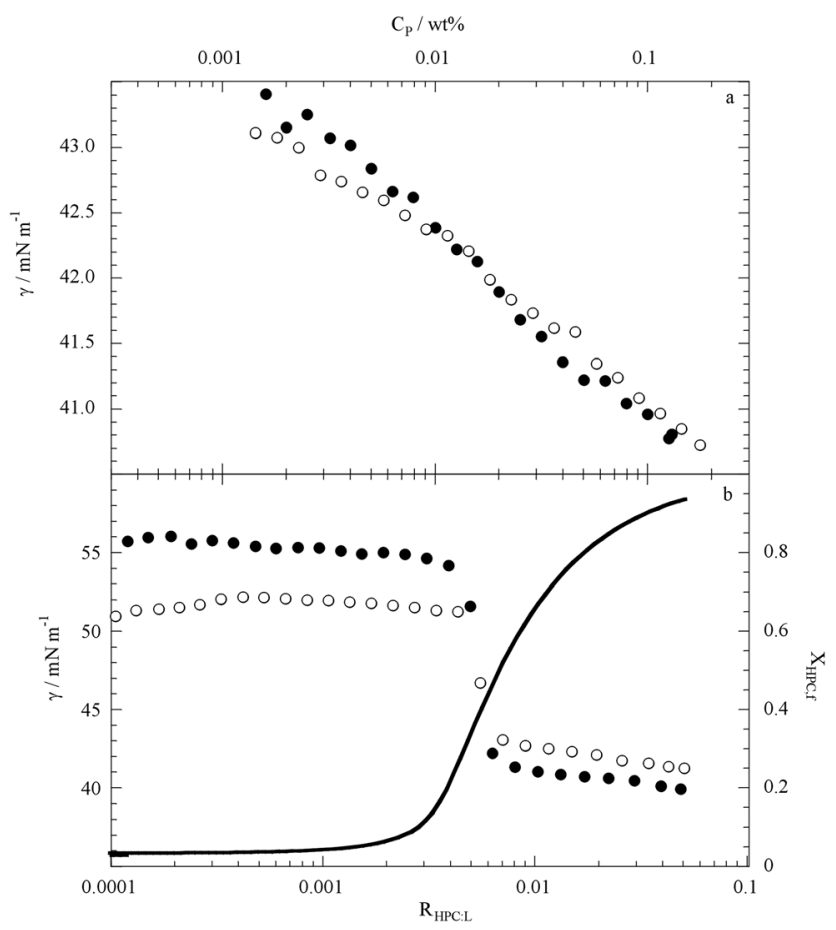

Fig. 7 Surface tension of aqueous HPC mixtures as a function of the polymer concentration: (a) the solvents are water $(\bullet)$ and water $+\mathrm{NaCl}$ (O); and (b) the solvents are water + Laponite RD (๑) and water +

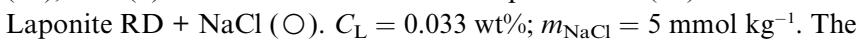
line is the fraction of non-adsorbed HPC calculated from ITC data (see text). 
area $\left(A_{\mathrm{P}}\right)$, that is, $49.7 \pm 1.3$ and $61.1 \pm 1.1 \mathrm{~m}^{2} \mathrm{~g}^{-1}$, respectively. From the model-projected surface areas ${ }^{36}$ the $A_{\mathrm{P}}$ value of $c a$. $1800 \mathrm{~m}^{2} \mathrm{~g}^{-1}$ is obtained and therefore one can conclude that the polymer at the interface presents loops and tails to a large extent. Such a configuration agrees with the polymer hydrophilic nature. Similar conclusions were drawn ${ }^{37}$ by surface light scattering experiments, which also showed that the HPC molecular mass does not play a relevant role. Moreover, we can state that the salt addition generates a slightly more flat polymer layer configuration than that observed in water. This result can be explained considering that the presence of $\mathrm{NaCl}$ reduces the HPC solubility in water because the salt apparently weakens the hydrogen bonding between HPC and water ${ }^{34}$ and the polymer escapes from the solvent to the interface, consequently.

The Laponite RD addition is very intriguing (Fig. 7b) because it dramatically alters not only the $\gamma$ values but also the shape of the $\gamma v s . C_{\mathrm{P}}$ trend. Namely, in the low $C_{\mathrm{P}}$ regime, it generates $\gamma$ values larger than those in the corresponding solvent (water or water $+\mathrm{NaCl}$ ) without Laponite $\mathrm{RD}$. This finding is consistent with the HPC adsorption onto the Laponite RD surface, which lowers the polymer chemical potential in solution and therefore $\gamma$ increases. Upon the polymer addition, $\gamma$ suddenly decreases approaching a constant value that is close to the value in the absence of Laponite RD. As Fig. 7b shows, $\mathrm{NaCl}$ does not alter the $\gamma$ vs. $C_{\mathrm{P}}$ trend in the presence of Laponite RD.

\section{Discussion}

The adsorption of a polymer at the solid/liquid interface involves a series of microscopic aspects that can differently contribute to the energetics of the entire process.

In particular, one observes the partial rupturing of the waterpolymer and water-nanoparticle bonds and the formation of polymer-nanoparticle interactions. Given that $\Delta H^{\circ}$ ads $<$ 0 (Fig. 3), the polymer-nanoparticle interactions are the dominant forces. This finding agrees with reports ${ }^{23}$ on the adsorption of poly(ethylene-glycol), poly(propylene-glycol) and Pluronics onto Laponite RD. The entropy change, in principle, is the result of three contrasting effects: (i) the loss of configuration freedom of the polymer in the adsorbed state; (ii) the release of ions from the Laponite RD surface caused by the polymer adsorption and (iii) the water release (de-hydration) from the polymer. The strong entropy change confirms that the constraints of the polymer motion at the solid/liquid interface are the dominant entropic factors (Fig. 3). Nowicki ${ }^{38}$ calculated that the polymer attached to the colloidal particle decreases its entropy. This result agrees with the $R_{\mathrm{h}}$ data that indicate a large number of contact points between the polymer and the nanoparticle. This result is peculiar for polymer adsorbed onto disk-like nanoparticles as also evidenced by neutron scattering experiments. ${ }^{27,39}$ Differently, spherical nanoparticles lead to a hairy adsorbed polymer layer and in this case the adsorption was entropy driven. ${ }^{40}$

Temperature change affects the energetics of the adsorption process but the entropy-enthalpy compensation generates little changes in the $\Delta G^{\circ}$ ads with temperature. Concerning this aspect it is noteworthy to highlight the importance of direct measurements of thermodynamic properties. The issue on the comparability of the enthalpy derived from van't Hoff and calorimetric methods is still a debated matter. ${ }^{41-43}$ In our case, based on the negative enthalpy change and the van't Hoff equation, one would expect a positive $\Delta G^{\circ}$ ads $v s$. temperature slope, that is opposite to the experimental findings (Fig. 3). The correlation of $\Delta G^{\circ}$ ads to temperature through the classical van't Hoff equation might be inappropriate because of the presence of supramolecular interactions (stoichiometry and polydispersity), which might be largely influenced by temperature variation. For the polymer/ cyclodextrin inclusion complex formation, discrepancy between the enthalpies derived by the two methods was observed. ${ }^{44}$ In our case, we found that the $Z^{*}$ parameter is not constant (Fig. 3) and therefore the $\delta Z^{*} / \delta T$ contribution should be considered in the van't Hoff approach. Actually, this correction term cannot be rigorously calculated and, furthermore, if charged systems are considered (like Laponite RD) the $\delta Z^{*} / \delta T$ contribution can be the dominant effect due to the large pre-factor of the $\delta Z^{*} / \delta T$ derivative and the non-null derivative value ${ }^{42}$ as observed here (Fig. 3). Nevertheless, it is straightforward that only the calorimetric experiments provide direct and unambiguous insights into the heat exchange occurring during a given process and this is particularly important for supramolecular associative processes in solution. ${ }^{23,44-47}$

As soon as the thermodynamics of the process in the bulk phase is well described, the aqueous phase/air interfacial properties can be quantitatively interpreted. The $\gamma v s . C_{\mathrm{P}}$ profile can be understood to the light of the fraction of free HPC in solution $X_{\mathrm{HPC}, \mathrm{f}}$ (calculated from the adsorption isotherm data). Fig. 7b illustrates that $X_{\mathrm{HPC}, \mathrm{f}}$ is nearly negligible at low $C_{\mathrm{P}}$ while it increases reaching a nearly unitary value at larger concentration. It is interesting that the shapes of the curves in Fig. $7 \mathrm{~b}$ are rather similar and that to the sharp $X_{\mathrm{HPC}, \mathrm{f}}$ change corresponds the sharp $\gamma$ decrease. From this evidence one deduces that the steplike change in the $\gamma v s$. $C_{\mathrm{P}}$ profile in the presence of Laponite RD reflects the saturation of the nanoparticles surface and that the polymer covering Laponite RD is not surface active or, at least, it is less surface active than the unbound polymer.

The salt addition might represent a strategy to control the structure of the HPC-covered Laponite RD. It is known that the HPC solvophilicity in water can be influenced by concentrated monovalent salts, ${ }^{9,20,34}$ and that the Laponite RD + water mixture is strongly sensitive to electrolytes. ${ }^{22}$ We showed that the cloud point of HPC can be altered by adding the clay nanoparticles and that, compared to HPC in water, HPC in water + Laponite RD has a cloud behavior very sensitive to the salt addition.

The HPC adsorption isotherms in the presence of salts showed a peculiarity of $\mathrm{NaCl}$ (Table 1). This effect reflects neither the change of the hydrated ionic radii of the cations nor the chaotropic series. On the other hand one has to consider that the Laponite RD nanoparticles are charged because they release $\mathrm{Na}^{+}$ ions from the disk-face surface into the aqueous phase. Thus, one may suppose that the $\mathrm{NaCl}$ effect is ascribable to the sodium common ion. To clarify this aspect one can calculate that under our experimental conditions and considering a charge of $-700 \mathrm{e}$ for each disk, ${ }^{22}$ the Laponite RD dissociation generates a sodium concentration in solution of $c a .4 \mathrm{mmol} \mathrm{kg}^{-1}$. Being that this value is comparable to the concentration of the added salt, one expects that the ion release from Laponite RD is reduced in the presence of $\mathrm{NaCl}$ due to the common ion effect. To the light of this calculation one supposes a slightly small contribution of the Laponite RD dissociation to $\Delta H^{\circ}$ ads. Consequently, the decrease 
of $\Delta H^{\circ}$ ads in $\mathrm{NaCl}$ is explained as well as the opposite results of other salts for which the common ion effect cannot be invoked. The common ion phenomenon takes into account the $Z^{*}$ values that evidence the $\mathrm{NaCl}$ peculiarity (Table 1). Accordingly, $\mathrm{LiCl}$ and $\mathrm{KCl}$ decrease the maximum amount of HPC adsorbed per Laponite $\mathrm{RD}$ cell unit mole while $\mathrm{NaCl}$ does not alter the stoichiometry of the adsorption process. The negligible influence of $\mathrm{NaCl}$ on the aqueous phase/air surface properties agrees with the unchanged polymer/Laponite RD stoichiometry upon $\mathrm{NaCl}$ addition as evidenced by ITC experiments.

\section{Conclusions}

The aim of the work was designing nanostructures in aqueous media that are inexpensive, biocompatible, environmentally friendly and advanced for potential specific purposes. Calorimetric experiments allowed us to determine the thermodynamics of the adsorption of a thermosensitive polymer HPC onto the nanoclay surface in aqueous solution. From the ITC data analysis it emerged that the adsorption process is favored and enthalpy driven. The HPC freedom at the nanoparticle/aqueous phase interface is reduced compared to that in the bulk phase. The knowledge of the adsorption equilibrium in the bulk allowed us to explain the air/solution interface properties. The role played by the salt addition is also interesting because the HPC cloud point in the presence of Laponite RD is highly affected and the polymer adsorption onto the nanoparticle is sensitive to the nature of the electrolyte showing a peculiarity for sodium ion that is the one released by Laponite RD.

The importance of direct measurements of the thermodynamic properties in supramolecular systems is remarked for a correct interpretation of the energetics of the involved processes.

We conclude that the nanoparticles functionalization triggered by temperature and/or inorganic salts opens up new routes for the control of the solid surfaces with the aim of obtaining smart materials.

\section{Acknowledgements}

The work was financially supported by the University of Palermo (Italy) and COFIN 2008 (Prot. 2008RH3FCW_002). Azelis Italia S.r.1. is acknowledged for kindly providing the Laponite RD sample.

\section{References}

1 G. Cavallaro, G. Lazzara and S. Milioto, Langmuir, 2011, 27, $1158-$ 1167.

2 G. Lazzara, S. Milioto, M. Gradzielski and S. Prevost, J. Phys. Chem. $C, 2009,113,12213-12219$.

3 R. N. Tharanathan, Trends Food Sci. Technol., 2003, 14, 71-78.

4 M. Hassan-Nejad, J. Ganster, A. Bohn, M. Pinnow and B. Volkert, Macromol. Symp., 2009, 280, 123-129.

5 Y. Guan, Y. Zhang, T. Zhou and S. Zhou, Soft Matter, 2009, 5, 842 849.

6 R. De Lisi, G. Lazzara, S. Milioto and N. Muratore, J. Phys. Chem. $B, 2004,108,1189-1196$.

7 L. Robitaille, N. Turcotte, S. Fortin and G. Charlet, Macromolecules, 1991, 24, 2413-2418.

8 I. W. Hamley, Soft Matter, 2010, 6, 1863-1871.
9 J. Chik, S. Mizrahi, S. Chi, V. A. Parsegian and D. C. Rau, J. Phys. Chem. B, 2005, 109, 9111-9118.

10 G. Giachi, C. Capretti, N. Macchioni, B. Pizzo and I. D. Donato, J. Cult. Heritage, 2010, 11, 91-101.

11 I. Bobowska, P. Wojciechowski and T. Halamus, Polym. Adv. Technol., 2008, 19, 1860-1867.

12 J. Bajdik, J. Regdon, T. Marek, I. Eros, K. Suvegh and K. PintyeHòdi, Int. J. Pharm., 2005, 301, 192-198.

13 C. W. Chang, A. van Spreeuwel, C. Zhang and S. Varghese, Soft Matter, 2010, 6, 5157-5164.

14 R. M. Guillermic, A. Salonen, J. Emile and A. Saint-Jalmes, Soft Matter, 2009, 5, 4975-4982.

15 R. De Lisi, G. Lazzara, S. Milioto and N. Muratore, Langmuir, 2006, 22, 8056-8062.

16 I. Boucenna, L. Royon, P. Colinart, M. A. Guedeau-Boudeville and A. Mourchid, Langmuir, 2010, 26, 14430-14436.

17 S. L. Tawari, D. L. Koch and C. Cohen, J. Colloid Interface Sci., 2001, 240, 54-66.

18 J. Gao, G. Haidar, X. Lu and Z. Hu, Macromolecules, 2001, 34, 2242 2247.

19 G. Cavallaro, D. I. Donato, G. Lazzara and S. Milioto, J. Phys. Chem. C, 2011, 115, 20491-20498.

20 C. Bonnet-Gonnet, S. Leikin, S. Chi, D. C. Rau and V. A. Parsegian, J. Phys. Chem. B, 2001, 105, 1877-1886.

21 D. Malakhov and M. Abou Khatwa, J. Therm. Anal. Calorim., 2007, 87, 595-599.

22 B. Ruzicka and E. Zaccarelli, Soft Matter, 2011, 7, 12681286.

23 R. De Lisi, G. Lazzara, R. Lombardo, S. Milioto, N. Muratore and M. L. Turco Liveri, Phys. Chem. Chem. Phys., 2005, 7, 39944001.

24 R. De Lisi, G. Lazzara, S. Milioto and N. Muratore, Chemosphere, 2007, 69, 1703-1712.

25 A. Nelson and T. Cosgrove, Langmuir, 2004, 20, 10382-10388.

26 K. Chiad, S. H. Stelzig, R. Gropeanu, T. Weil, M. Klapper and K. Mullen, Macromolecules, 2009, 42, 7545-7552.

27 R. De Lisi, M. Gradzielski, G. Lazzara, S. Milioto, N. Muratore and S. Prévost, J. Phys. Chem. B, 2008, 112, 9328-9336.

28 J. Tellinghuisen, Anal. Biochem., 2007, 360, 47-55.

29 T. Kollár, Z. Kónya, I. Pálinkó and I. Kiricsi, J. Mol. Struct., 2001, 563-564, 417-420.

30 K. Sharp, Protein Sci., 2001, 10, 661-667.

31 R. R. Krug, W. G. Hunter and R. A. Grieger, J. Phys. Chem., 1976, 80, 2335-2341.

32 P. B. Laxton and J. C. Berg, J. Colloid Interface Sci., 2006, 296, 749755.

33 A. Dupuis, N. Guo, Y. Gao, N. Godbout, S. Lacroix, C. Dubois and M. Skorobogatiy, Opt. Lett., 2007, 32, 109-111.

34 X. Xia, S. Tang, X. Lu and Z. Hu, Macromolecules, 2003, 36, 36953698.

35 S. A. Chang and D. G. Gray, J. Colloid Interface Sci., 1978, 67, 255 265.

36 C. S. Gau, H. Yu and G. Zografi, Macromolecules, 1993, 26, 2524 2529.

37 E. J. McNally and G. Zografi, J. Colloid Interface Sci., 1990, 138, 6168.

38 W. Nowicki, Macromolecules, 2002, 35, 1424-1436.

39 A. Nelson and T. Cosgrove, Langmuir, 2004, 20, 2298-2304.

40 R. De Lisi, G. Lazzara, S. Milioto and N. Muratore, Phys. Chem. Chem. Phys., 2008, 10, 794-799.

41 J. B. Chaires, Biophys. Chem., 1997, 64, 15-23.

42 A. Holtzer and M. F. Holtzer, J. Phys. Chem., 1974, 78, 1442-1443.

43 P. Taboada, V. Mosquera, D. Attwood, Z. Yang and C. Booth, Phys. Chem. Chem. Phys., 2003, 5, 2625-2627.

44 R. De Lisi, G. Lazzara and S. Milioto, Phys. Chem. Chem. Phys., 2011, 13, 12571-12577.

45 M. Tiné, M. Alderighi, C. Duce, L. Ghezzi and R. Solaro, J. Therm. Anal. Calorim., 2011, 103, 75-80.

46 I. V. Terekhova, A. O. Romanova, R. S. Kumeev and M. V. Fedorov, J. Phys. Chem. B, 2010, 114, 12607-12613.

47 C. De Stefano, A. Gianguzza, D. Piazzese, N. Porcino and S. Sammartano, Biophys. Chem., 2006, 122, 221-231. 